\title{
Strength and Fracture Toughness of Heavy Concrete with Various Iron Aggregate Inclusions
}

\author{
Yu-Cheng Kan ${ }^{1)}$, Kuang-Chih Pei ${ }^{2)}$ and Chien-Lung Chang ${ }^{1)}$
}

1) Department of Construction Engineering, Chaoyang University of Technology, Taiwan, R.O.C.

2) Institute of Nuclear Energy Research, Taiwan, R.O.C.

\begin{abstract}
This paper presents an experimental study dealing with mechanical properties and fracture toughness of heavy concrete that is used mostly in the construction of radiation shielding structures. The mixes used herein are developed according to the ones adapted in a Taipower's nuclear power plant in Taiwan; the basic mechanical properties tests conducted conform to the ASTM and the fracture properties are determined through the testing method proposed by Karihaloo and Nallathambi. Test results revealed that the elastic modulus of heavy concrete is higher than regular mortar and is increasing with the increase of iron ore. The compressive strength of heavy concrete also turns out to increase with the growth of iron ore content; while, the tensile strength appears decrease with the increase of iron ore content. Fracture toughness of the concrete including iron ore appears lower than that of normal concrete.
\end{abstract}

\section{INTRODUCTION}

As the growth of human population and industrial needs, nuclear technology directs human's life toward the use of artificial energy to implement the conventional energy sources, which are getting shorter and shorter on earth. However, the issue of its potential impact to environment, which could lead to catastrophic crisis attracts more and more attentions and discussions. Degradation of radiation shielding structure, which may lead to radiation leakage is one of the most crucial issue to civil engineers since more mechanism of concrete has been figured out and more concrete technology has been innovated. Cracks always take place prior to deterioration or failure of a concrete structure. The research area of studying cracking of concrete is referred to as fracture mechanics of concrete [1,2]. It is thought that concrete initiates its crack as the fracture toughness that is always defined quantitatively in terms of critical stress intensity factor $\mathrm{K}_{\mathrm{C}}$ or fracture energy $\mathrm{G}_{\mathrm{C}}$ has been reached $[3,4]$.

Plenty of research efforts have been conducted in studying the fracture toughness of normal concrete with various mixtures [5-8]; while few researches have been performed concerning with heavy concrete for its strengths as well as fracture property. ACI Manual of Concrete Practice [9] provides thorough procedures for measuring, mixing, transporting and placing. Also, typical unit weights and compressive strengths of heavy concrete with different types of aggregates are given as well. Yet no information dealing with the fracture property of heavy concrete has been reported. As environmental protection becomes a significant issue, more efforts on advance techniques of inspection and repairing assessment of shielding structure have to be made. Thus, crack propagation of heavy concrete, which could reflect structural behavior and be related to the residual strength of concrete structure should be figured out.

Swartz and his workers [10-12] used pre-cracked specimen and dye technique to find that the crack front of concrete beam is not uniform through the beam thickness. The presence of fairly substantial "side lips" then raises the question whether or not the assumption made for the conventional RC analysis that the neutral axis is uniform distributed along the beam thickness is valid as analyzing a cracked concrete element. The shape of crack front seems to provide an approach more feasible and more straightforward to evaluate the loading capacity of concrete beam. In 1996, Kan and Swartz [13] have used the cracked section to provide a means to evaluating the residual strength of pre-cracked beam from the cracked section that revealed by the dye. They found that a correction factor corresponding to various concrete mixtures should be introduced to compensate the difference of load capacities between the measured and the evaluated. In this work, the crack fronts of normal concrete and lightweight concrete have been observed.

From the aspect of fracture mechanics, there is a fracture process zone in front of the crack tip of concrete as crack propagates. Recently, there has been a number of proposals being suggested to RILEM [14], such as Hillerburg's work of fracture model [15], Bazant's size effect model [16], Jenq and Shah's two-parameter model [17] and Karihaloo and Nallathambi's effective crack model [18], which all provide methods to determine fracture properties of concrete. However, few researches have been conducted to evaluate the strength of cracked concrete element purely from the real developed crack front. It is felt valid to employ the concept of fracture mechanics to implements the shortage of the conventional analysis for remaining strength of cracked concrete beam.

The objective of this research work makes an attempt to investigate the mixture, fabrication and many fundamental engineering properties of heavy concrete including strengths and fracture toughness, in terms of critical stress intensity factor, under the influences of various content of iron shots and ore. The testing results have been compared with regular mortar and 
are also presented.

\section{TESTING PROGRAM}

\section{Material Preparations}

Aggregate

Different from normal concrete, the main feature of heavy concrete is the inclusion of metallic fillers, which usually choose ilmenite, limonite-goethite, serpentine, magnetite, barite, ferrophosphorous, steel aggregate and iron shot as aggregates. In this study, iron ore and iron shot are adopted as concrete aggregates. The iron ore used herein was imported from Brazil. It has a maximum grain size of $9.5 \mathrm{~mm}$ along with a fineness modulus of 3.04 and a specific gravity is 4.8

Table 1 Chemical analysis of iron ore in percentage*

\begin{tabular}{lc}
\hline Item & $\%$ \\
\hline $\mathrm{Fe}$ & 66.480 \\
$\mathrm{Mn}$ & 0.124 \\
$\mathrm{P}$ & 0.017 \\
$\mathrm{~S}$ & 0.004 \\
$\mathrm{Al}_{2} \mathrm{O}_{3}$ & 0.610 \\
$\mathrm{SiO}_{2}$ & 3.590 \\
$\mathrm{~Pb}$ & 0.003 \\
$\mathrm{Zn}$ & 0.001 \\
$\mathrm{Cu}$ & 0.001 \\
$\mathrm{TiO}_{2}$ & 0.047 \\
$\mathrm{~K}_{2} \mathrm{O}$ & 0.008 \\
$\mathrm{Others}$ & \\
\hline * Information was provided by local supplier.
\end{tabular}

measured from the tests complying with ASTM Spec. [19-20]. The typical composition of iron ore is illustrated in Table 1 for reference. The iron ore is thus selected with a minimum amount of ferrophosphorous since it has been reported that ferrophosphorous when used in Portland cement will generate flammable and possibly toxic gases. Two types of iron shot manufactured locally are used herein and have a specific gravity of 7.4 along with maximum grain sizes of $1.75 \mathrm{~mm}$ and 2.0 $\mathrm{mm}$.. It appears that smaller particles show a less tendency to segregate, even though their densities are higher. On the other hand, regular sand with a maximum grain size of $4.75 \mathrm{~mm}$ (No.4 sieve) and fineness modulus of 3.17 is also used to fabricate mortar specimens for the purpose of comparison with heavy concrete.

\section{Cement}

Type I Portland cement is the only kind used for the entire experiment following the ASTM C150 or ASTM C595 for conventional concrete; the cement performance is suitable for use in heavy concrete. It is advisable not to use Type III cement or accelerators in order to avoid high and rapid hydration heat that may result cracking. [9]

\section{Mixture of Concrete}

To investigate the effect of metallic aggregate on the mechanical properties of heavy concrete, the mixtures of concrete are designated with a unique water-to-cement ratio $\mathrm{W} / \mathrm{C}=0.48$, and with $0 \%, 10 \%, 20 \%, 40 \%$ and $48.8 \%$ of metallic aggregates in volume in the testing program. The latest mixture has been used in some nuclear power plant in Taiwan. In Table 2, five mixtures used herein are designated and shown. It is noted that the amount of iron shot is fixed at $9.2 \%$ for all mixtures while the iron ore is varied, therefore the unit weight of concrete increases with the increase of metallic aggregate content. The corresponding unit weights (or densities) of the mixtures are $2188,2653,2874,3316$ and $3510 \mathrm{~kg} / \mathrm{m}^{3}$, respectively. Slump and air content of fresh concrete of each mixture are also illustrated in Table 2, which have conformed to the needs of workability. It is noted that some admixtures such as water reducer and superplasticizer and not advisable in the mixture of heavy concrete in order to ascertain to the minimum requirement of water which supplies sufficient amount of hydrogen atoms.[9] 
Table 2 Mixtures of concrete with various metallic aggregates

\begin{tabular}{lrrrrr}
\hline Mix & I & II & III & IV & V \\
\hline Water & 266 & 274 & 277 & 283 & 285 \\
Cement & 643 & 643 & 643 & 643 & 643 \\
Iron shot & & & & & \\
$\quad$ S550 & 0 & 348 & 348 & 348 & 348 \\
$\quad$ S660 & 0 & 333 & 333 & 333 & 333 \\
Iron ore & 0 & 38 & 459 & 1478 & 1901 \\
Sand & 1279 & 1017 & 755 & 231 & 0 \\
Unit weight & 2188 & 2653 & 2874 & 3316 & 3510 \\
air (\%) & 1.6 & 1.7 & 1.9 & 2.2 & 2.3 \\
\hline
\end{tabular}

Note: the unit is based on $\mathrm{kg} / \mathrm{m}^{3}$.

\section{Mixing and Curing}

The procedure for mixing heavy concrete is similar to conventional concrete. In a typical mixing procedure, the iron ore and iron shot are mixed first, followed by cement and then water, as same as mixing of regular concrete. However, due to higher specific gravities of both iron ore and iron shot, too much compacting vibration that can lead to segregation has to be avoided. In addition, the absorption of aggregates obtained from laboratory are $1.19 \%$ for iron ore and negligible for iron shot. Trial mix for each mixture has been engaged until a good workability and sufficient strength gain is achieved. In the mean time, air content is also measured from fresh concrete for each mix, which could provide useful data to figure out the amount of voids. All concrete specimens were cast in molds for one day and then placed in water for 28 days prior to testing; the specimens for cracking analysis were placed in air for another three days before the process of pre-cracking and dying.

\section{Testing Specimens}

Four types of specimens made from the above five mixtures were fabricated in this testing program. The $\Phi 15 \times 30 \mathrm{~cm}$ cylinders were used to determine the physical properties of concrete including modulus of elasticity and wave velocity. The $\Phi 10 \mathrm{x} 20 \mathrm{~cm}$ cylinders were mainly tested for compressive strength and tensile strength. The cubic specimens of $15 \mathrm{x} 15 \mathrm{x}$ $15 \mathrm{~cm}$ in dimension with an additional No. 6 steel bar being planted into the specimens, which also follows the ASTM, was used for pullout test in order to determine the pullout strength of concrete. Three-point bending beam specimen of $10 \times 10 \mathrm{x}$ $35 \mathrm{~cm}$ in dimension was employed for flexural test. This was used to determine the rupture modulus of concrete. In addition, single-edge-notched beams were fabricated with a notch in the middle of beam as a crack starter, as illustrated in Fig. 1. They were used to determine fracture toughness of cracked beam.



Fig. 1 Testing setup for single-edge-notch beam

\section{Testing Procedure}

Testing procedures of all fundamental mechanical properties conform to the ASTM Specifications [21-25]. Fracture toughness of heavy concrete, in terms of stress intensity factor, is evaluated by the method suggested by Karihaloo and Nallathambi [18]. In this method, the single notched beams were tested in three-point bending on a universal testing machine. Load and displacement data are recorded simultaneously before peak load being reached. Also, only the region prior to peak of the curve is needed and no softening curve is required. Thus, the formula to evaluate the critical stress intensity factor $\mathrm{K}_{\mathrm{IC}}{ }^{\mathrm{e}}$ can be expressed as

in which,

$$
K_{I C}^{e}=\sigma_{n} \sqrt{a_{e}} F(\alpha)
$$




$$
F(\alpha)=\frac{1.99-\alpha(1-\alpha)\left(2.15-3.93 \alpha+2.70 \alpha^{2}\right)}{(1+2 \alpha)(1-\alpha)^{3 / 2}}
$$

where $\alpha=a_{e} / W$ is the ratio of critical effective crack depth to the beam depth and can be determined from the following formula

$$
\frac{a_{e}}{W}=\varepsilon_{1}\left(\frac{\sigma_{n}}{E}\right)^{\varepsilon_{2}}\left(\frac{a_{p}}{W}\right)^{\varepsilon_{3}}\left(1+\frac{g}{W}\right)^{\varepsilon_{4}}
$$

In the above expression, $\varepsilon 1, \varepsilon 2, \varepsilon 3$ and $\varepsilon 4$ are coefficients of regression calibrated from experimental data that considering the notch depth $\mathrm{a}_{\mathrm{p}}$, and the grain size $\mathrm{g}$. In addition, the modulus of elasticity $\mathrm{E}$ is obtained from the cylinder test.

Wave velocity is measured from a cylinder through impact-echo method [26]. The testing system comprises an impact device, a receiver and a computer with data acquisition interference. An impact source excites a compressive stress wave (Pwave) at a point of one side. The receiver is placed on the same side to record the time duration wave traveling to and back from the other side. The wave velocity is thus determined by dividing the path length by the time duration.

\section{RESULTS AND DISCUSSIONS}

\section{Mechanical Properties of Concrete}

\section{Compressive Strength}

The inclusion of heavy aggregates in concrete does not increase the concrete strength as previously expected to reflect their characteristics of higher strength and higher density. This can attribute to the cracking types, which takes place as the crack propagating in the paste as shown on path 2 in Fig. 2. This can be observed by the testing results of compressive strengths as shown in Figure 3 that an increase of iron ore and iron shot amount makes a little growth in concrete strength. In fact, an inclusion of $40 \%$ of heavy aggregate in volume only raises the compressive strength up to $5 \%$ higher than the strength of regular mortar.

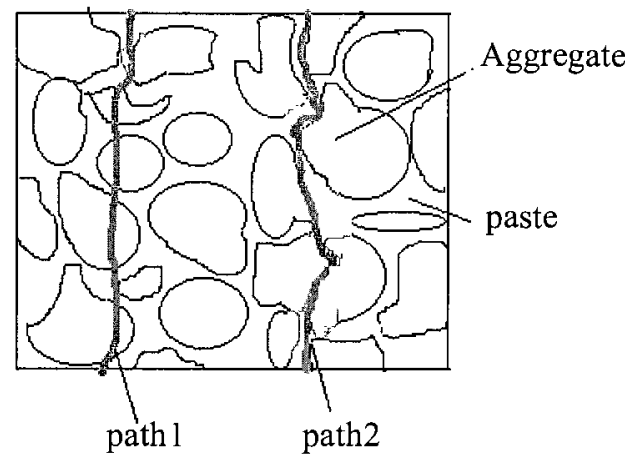

Fig. 2 Two possible cracking paths of concrete

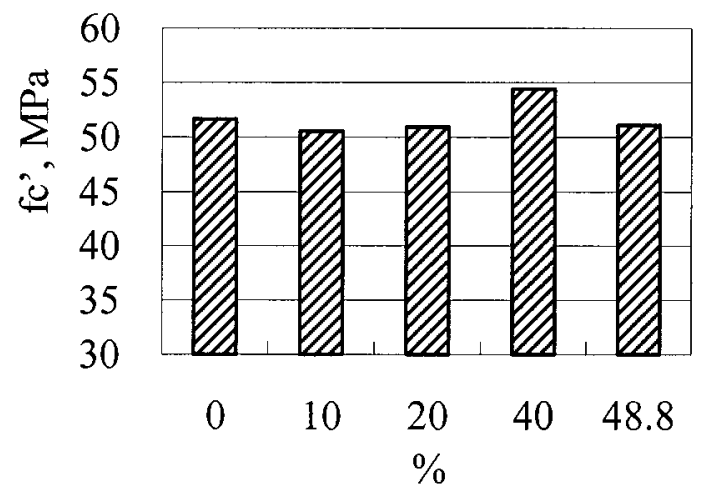

Fig. 3 Compressive strengths for concrete with various metallic aggregates

Table 3 Mechanical properties of concrete with various metallic aggregates

\begin{tabular}{crrrrr}
\hline Mix & I & II & III & IV & \multicolumn{1}{c}{ V } \\
\hline fc' (Mpa) & 51.6 & 50.6 & 50.9 & 54.4 & 51.0 \\
Ec (Gpa) & 20.9 & 25.9 & 26.9 & 34.2 & 31.1 \\
ft' (Mpa) & 3.42 & 2.90 & 2.98 & 2.49 & 2.42 \\
fr' (Mpa) & 6.84 & 8.05 & 6.84 & 6.91 & 6.84 \\
u (Mpa) & 10.4 & 12.1 & 8.46 & 9.35 & 10.0 \\
V (m/sec) & 3580 & 3458 & 3385 & 3225 & 3245 \\
$\mathrm{~K}_{\mathrm{IC}}(\mathrm{MPa} \sqrt{\mathrm{m}})$ & 986 & 1.031 & 1012 & 1040 & 1105 \\
\hline
\end{tabular}




\section{Splitting Tensile Strength}

The splitting tensile test was used to determine the tensile strengths of concrete with various heavy aggregate inclusions. From Table 3, it is observed that the tensile strength appears decreasing with the increase of the amount of iron ore. An inclusion of $48.8 \%$ of heavy aggregate in volume reduces tensile strength down to $70 \%$ as compared to normal concrete mortar. Meanwhile, an observation on the fractured face of split cylinder shows that there are many pullout cavities on the surface on which the iron shot are located.

\section{Modulus of Rupture}

Three-point bending flexural test is adopted to estimate the modulus of rupture of heavy concrete. It is shown in Table 3 that except for the mixture with inclusion of $10 \%$ of heavy aggregate, no big difference of modulus of rupture is found among the mixtures of concrete. The reason for this can be attributed to the fracture type that the crack propagates in the paste along the aggregate rather than through the aggregate.

\section{Bond Strength}

The nominal bond strengths for various concrete were obtained based on the pullout test following the ASTM. The testing results are shown in Table 3, which show that the tendency of bond strengths varying with the inclusions of heavy aggregates is similar to that of modulus of rupture. In addition, the cracking type observed from the surface of all specimens show that splitting failure dominates instead of pullout failure for all concrete mixtures.

\section{Elastic Modulus}

The elastic modulus of all concrete measured in this study is referred to 28 days of age. The curing condition of specimens is the same as those for compressive strength. Test results revealed that the elastic modulus of heavy concrete is higher than regular concrete mortar and is increasing with the increase of iron ore. As is shown in Fig.4, it can be seen that a heavy aggregate inclusion of $48.8 \%$ in volume makes the elastic modulus of concrete raise to about 1.5 times that of regular mortar, but does not make the compressive strengths too much difference as previously mentioned.

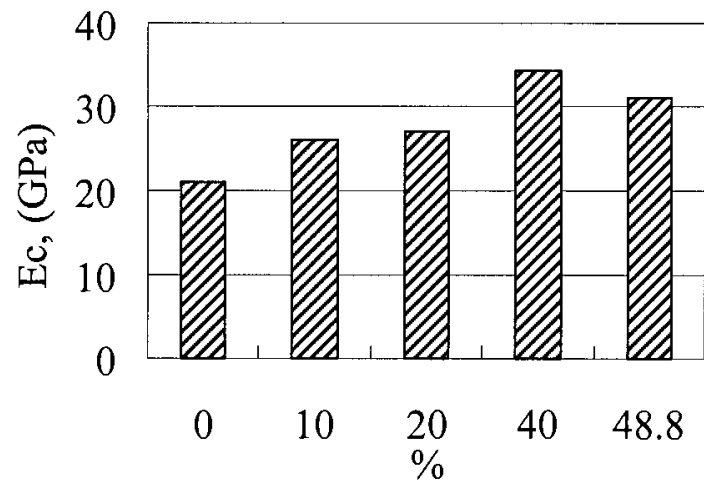

Fig. 4 Modulus of elasticity for concrete with various metallic aggregates

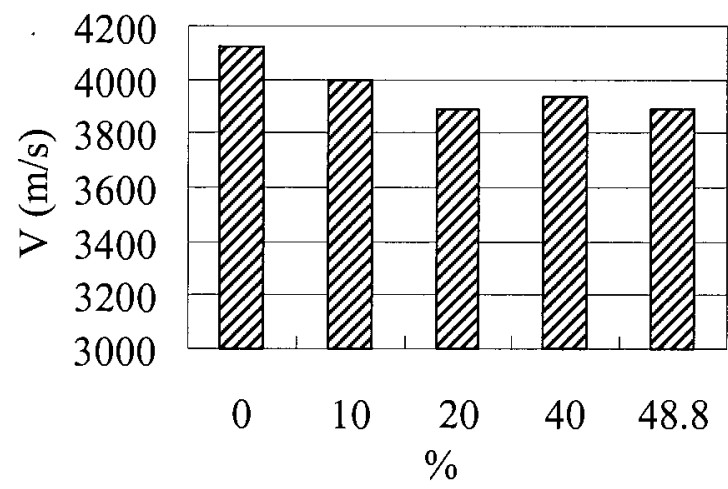

Fig. 5 Wave velocity for concrete with various metallic aggregates

\section{Wave Velocity}

The testing results show that the wave velocity of heavy concrete decreases as iron ore increasing as shown in Fig. 5, which implies that more iron ore introduce more voids in heavy concrete. This is consistent with an inspection on the air content test of fresh concrete. The reason for this might attribute to the gas induced by chemical reactions between cement and some chemical constituents of iron ore.

\section{Fracture Toughness}

The mode I fracture toughness of heavy concrete, in terms of stress intensity factor $\mathrm{K}_{\mathrm{IC}}$, which is evaluated by the method suggested by Karihaloo and Nallathambi. As being compared with regular concrete, it turns out that $\mathrm{K}_{\mathrm{IC}}$ of heavy concrete is a bit difference to regular mortar, but is lower than normal concrete based on a empirical formula proposed by John and Shah [27], as illustrated in Fig. 6. This may attribute to the particle size, which dominates the toughness of concrete rather than the particle strength itself. 
In addition, an observation on the cracked sections from those beams being pre-cracked due to bending and dyed shows that the feature of crack front of heavy concrete is similar to that of regular mortar- namely, the beam crack depth appears shorter in the middle than those near the sides.

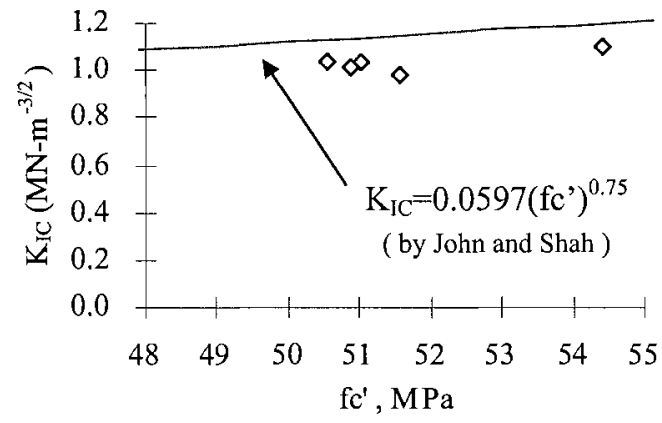

Fig. 6 Fracture toughness of heavy concrete compared with the empirical formula for normal high strength concrete by John and Shah

\section{CONCLUSIONS}

From the testing results, some conclusions can be drawn and summarized as follows:

1. The compressive and tensile strengths of heavy concrete did not show apparent difference from those of regular mortar of the same water-cement ratio. This can be explained by the fracturing type that crack propagates along, instead of through, the aggregate in the paste; however, modulus of elasticity turns out increasing as the increase of heavy aggregate.

2. Fracture toughness of heavy concrete made of iron ore and iron shot, in terms of critical stress intensity factor, is similar to that of regular mortar of the same water-cement ratio. However, it is found lower as being comparing with the formula proposed by John and Shah to predict the critical stress intensity factor normal concrete.

3. Wave velocity measured from heavy concrete displays decreasing with the increase of iron ore. This phenomenon appears consistent with the trend that air content increase with the increase of iron ore in the stage of fresh concrete.

4. The feature of crack front of heavy concrete is similar to that of regular mortar, namely, the beam crack depth appears shorter in the middle than those on the sides due to bending.

\section{NOMENCLATURE}

$\mathrm{a}_{\mathrm{e}} \quad=$ critical effective crack

$\mathrm{a}_{\mathrm{p}} \quad=$ notch depth

$\mathrm{B}=$ beam width

$\mathrm{E} \quad=$ modulus of elasticity

$\mathrm{F}(\alpha)=$ function of cracking characteristics

$\mathrm{f}_{\mathrm{c}}{ }^{\prime}=$ compressive strength

$\mathrm{f}_{\mathrm{r}}{ }^{\prime}=$ rupture of modulus

$\mathrm{f}_{\mathrm{t}}{ }^{\prime}=$ splitting tensile strength

$\mathrm{g}=$ grain size

$\mathrm{G}_{\mathrm{C}}=$ fracture energy or energy release rate

$\mathrm{K}_{\mathrm{C}}=$ critical stress intensity factor

$\mathrm{K}_{\mathrm{IC}}{ }^{\mathrm{e}}=$ critical stress intensity factor in Mode I fracture by Karihaloo and Nallathambi

$\mathrm{M}=$ bending moment

$\mathrm{u} \quad=$ pullout bond strength

$\mathrm{V}=$ wave velocity

$\mathrm{W}=$ beam depth

$\mathrm{W} / \mathrm{C}=$ water to cement ratio

$\alpha=$ ratio of depth to the beam depth

$\varepsilon_{\mathrm{I}} \quad=$ coefficients of regression

$\sigma_{\mathbf{n}}=$ normal stress 


\section{ACKNOWLEDGEMENT}

This research work is completed under the support, with the grant no. NSC 89-TPC-7-324-003, funded by the National Science Foundation in Taiwan and Taiwan Electrical Power Inc., which is sincerely appreciated. The equipment and technique assistance from the Institute of Nuclear Energy Research in Taiwan is also acknowledged.

\section{REFERENCES}

1. ACI Committee 446, "Fracture Mechanics of Concrete: Concept, Models, and Determination of Materials Properties", ACI 446.1R-91, American Concrete Institute, Detroit, MI., 1991.

2. Shah, S. P, Swartz, E. S. and Ouyang, C., Fracture Mechanics of Concrete, 1st ed., John Wiley \& sons, Inc., 1995.

3. Broek, D., Elementary Engineering Fracture Mechanics, 4th ed., Martinus Nijhoff Publishers, Dordrecht, 1986.

4. Kaplan, M. F., "Crack Propagation and the Fracture of Concrete," Journal of the American Concrete Institute, Vol. 58, No.5, 1961, pp. 591-610.

5. Naus, D. J. and Lott, J. L., "Fracture Toughness of Portland Cement Concretes," ACI Journal, Proceedings, Vol. 66, No. 6, 1969, pp. 481-489.

6. Nallathambi, P., Karihaloo, B. L., and Heaton, B. S., "Effect of Specimen and Crack Sizes, Water Cement Ratio and Coarse Aggregate Texture Upon Fracture Toughness of Concrete," Magazine of Concrete Research, Vol. 36, No.. 129, 1984, pp.227-236.

7. Hillerborg, A., "The theoretical Basis of a Method to Determine the Fracture Energy $\mathrm{G}_{\mathrm{F}}$ of Concrete," Materials and Structures, Vol. 18, No.106, July-August, 1985, pp. 291-296.

8. Petersson, P. E., "Crack Growth and Formation of Fracture Zones in Plain Concrete and Similar Materials," Report TVBM-1006, Division of Building Materials, Lund Institution of Technology, Sweden, 1981.

9. ACI Manual of Concrete Practice, "Heavyweight Concrete - Measuring, Mixing, Transporting and Placing," Part II, 304.3R, 1989.

10. Swartz, S. E. and Go, C. J., "Validity of Compliance Calibration to Cracked Concrete Beams in Bending," Experimental Mechanics, Vol. 24, No. 2, June 1984, pp. 129-134.

11. Swartz, S.E. and Refai, T., "Cracked Surface Revealed by Dye and Its Utility in Determining Fracture Parameters", in Fracture toughness and Fracture Energy: Test Method for Concrete and Rock, edited by Mihashi, H., et al., Balkema, Brookfield, VT, 1989, pp.509-520.

12. Liu, Z.-G., Swartz, S. E., and Hu, K. K., "Two Dimensional Finite Element Modeling of Crack Growth in Concrete Using Three Dimensional Damage Data," Micromechanics of Failure of Quasi-Brittle Materials, S. P. Shah and S. E. Swartz, M. L. Wang, ed. Elsevier Applied Science, June 1990.

13. Kan, Y.-C., and Swartz, S. E., "Evaluation of Residual Strength From the Cracked Sections of Concrete Beams," Proceedings, the Sixth East Asia-Pacific Conference on Structural Engineering \& Construction, 1998, pp.817-822.

14. RILEM 89-FMT, "Determination of Fracture Parameters $\left(\mathrm{K}_{\mathrm{IC}}{ }^{\mathrm{S}}\right.$ and $\left.\mathrm{CTOD}_{\mathrm{C}}\right)$ of Plain Concrete Using Three-Point Bend Tests," Materials and Structures, Vol. 23, No.138, 1990, pp. 457-460.

15. Hillerborg, A., Modeer, M., and Petersson, P.-E., "Analysis of Crack Formation and Crack Growth in Concrete by Means of Fracture Mechanics and Finite Elements", Cement and Concrete Research, Vol. 6, No.6, 1976, pp. 773-782.

16. Bazant, Z. P. and Oh, B. H., "Crack Band Theory for Fracture of Concrete", Materials and Structures, RILEM, Vol. 16, 1983, pp. 155-177.

17. Jenq, Y. S. and Shah, S. P., "Two Parameter Fracture Model for Concrete", Journal of Engineering Mechanics, ASCE, Vol. 111, No. 10, 1985, pp. 1227-1241.

18. Karihaloo, B. L. and Nalathambi, P., "Notched Beam Test: Mode I Fracture Toughness," in RILEM Report 5, Fracture Mechanics Test Methods for Concrete, Ed. by Shah, S. P., and Carpineteri, A., Chapman \& Hall, London, 1991, pp. 1-86.

19. ASTM Standards C127-88, Test Method for Specific Gravity and Absorption of Coarse Aggregate, 1988.

20.ASTM Standards C128-88, Test Method for Specific Gravity and Absorption of Fine Aggregate, 1988.

21 ASTM Standards C39-86, Test Method for Compressive Strength of Cylindrical Concrete Specimens, 1986.

22.ASTM Standards C293-79, Test Method for Flexural Strength of Concrete (Using Simple Beam with Center-Point Loading), 1979.

23.ASTM Standards C469-87, Test Method for Static Modulus of Elasticity and Poisson's Ratio of Concrete in Compression, 1987.

24. ASTM Standards C496-87, Test Method for Splitting Tensile Strength of Cylindrical Concrete Specimens, 1987.

25. ASTM Standards C900-87, Test Method for Pullout Strength of Hardened Concrete, 1987.

26. Malhotra, V. M. and Carino, N. J., CRC Handbook on Nondestructive Testing of Concrete, CRC Press, Inc. 1991.

27. John, P. and Shah, S.P, "Fracture Mechanics Analysis of High Strength Concrete", ASCE Journal of Materials, Vol.1, No. 4, 1989, pp.185-198. 